\title{
Significance of connective tissue proliferation in the breakdown of cartilage: a novel in vivo model
}

\author{
F B DE BRITO, A R MOORE, S ADHYA, A Y AL-DUAIJ, AND \\ D A WILLOUGHBY
}

From the Department of Experimental Pathology, St Bartholomew's Hospital Medical College, London

SUMMARY The implantation of homologous femoral head cartilage in subcutaneous tissues of random bred Wistar rats results in both subchondral and articular surfaces becoming overlaid by an adherent granulation tissue comprising predominantly fibroblast-like cells. The response of the tissue to cartilage encapsulated with cotton fibres was also similar but erosions, mainly subchondral, were more evident and proteoglycan loss markedly greater. The connective tissue response to cotton was the progressive formation of a foreign body granuloma comprising mononuclear cells, multinucleated giant cells, and fibroblasts with very few polymorphonuclear leucocytes.

Rheumatoid arthritis is a chronic inflammatory disorder in which bone and cartilage of articulating joints are slowly destroyed by a proliferating invasive granulomatous tissue called pannus. ${ }^{12}$ This is derived from the synovial membrane and its microvasculature and is histologically characterised by proliferating fibroblasts, variable numbers of macrophages, lymphocytes, and plasma cells, blood vessels, and occasional collagen fibres. ${ }^{3}$ Destruction of cartilage is believed to be caused by degradative enzymes produced by cells of the pannus and by cartilage. ${ }^{49}$ This has been borne out from studies conducted in vitro, which have shown that macrophages, fibroblasts, and chondrocytes can release connective tissue degrading enzymes and inflammatory mediators and can cause the loss of matrix from cartilage explants. These studies have also shown that both fibroblast and chondrocyte cell activities can be increased significantly after interacting with a macrophage derived factor, interleukin 1.

The need for in vivo models to improve our understanding of the process of cartilage breakdown and in the search for new therapeutics has recently been stressed by Rainsford. ${ }^{10}$ We have attempted this over the past few years by studying cartilage

Accepted for publication 3 March 1986.

Correspondence to Dr F B De Brito, Department of Experimental Pathology, St Bartholomew's Hospital Medical College, London EC1A 7BE. breakdown after implantation into preformed subcutaneous air pouches in rodents. These pouches bear cavity linings resembling synovial tissue in structure, ultrastructural appearance, histochemical properties, phagocytic ability, and response to injury. ${ }^{11} 12$ Matrix loss from cartilage implants, however, was not influenced either by inflammation of the cavity or by implantation in non-inflated subcutaneous tissues. ${ }^{13-15}$

More recently we have studied the effect of varying the way in which inflammation and soft tissue is presented to cartilage and have investigated the effect of implanting cartilage in close association with cotton. Implantation of cotton in subcutaneous tissues of rodents is known to stimulate a granulomatous inflammation concomitant with the growth of granulation tissue. ${ }^{1617}$ We have found that cartilage proteoglycan loss is accelerated in its presence, and we report on this and speculate on the mechanisms contributing to this breakdown.

\section{Materials and methods}

\section{A N I M A L S}

Random bred Wistar strain rats weighing 150-200 g of both sexes were used. These were obtained from a colony maintained by the animal house at St Bartholomew's Hospital. Male rats were used for all experiments. Female rats were used only as donors of cartilage. 
ISOLATION OF FEMORAL HEAD CARTILAGE Rats were killed by cervical dislocation and the skin overlying the hip joint swabbed with alcohol, then excised. The joint was palpated through the overlying gluteus maximus muscle and an incision made across the muscle, cutting a flake of bone from the greater trochanter and dividing the capsular ligament to expose the neck of the femur. Pressure was then applied to the upper leg to dislocate the joint. Tere's ligament was divided and the cartilage cap eased from the femoral head with bone cutters. The cartilages were kept at room temperature in minimum essential medium containing $200 \mathrm{U} / \mathrm{ml}$ penicillin (Gibco) and $1.0 \mathrm{mg} / \mathrm{ml}$ streptomycin (Gibco) and implanted within one hour of collection.

IMPLANTATION OF CARTILAGE AND COTTON; ASSESSMENT OF GRANULOMATOUS RES PONSE

A modification of the method of Meier et al of implanting cotton subcutaneously was used. ${ }^{16}$ Sterile rectangular $(0.5 \times 0.75 \mathrm{~cm})$ pieces of cotton of equal weight and roughly equal surface area and thickness were wrapped firmly around cartilages and allowed to soak in antibiotic supplemented medium for a short time before implanting subcutaneously in one flank of the rats. Cartilages treated similarly but without cotton were implanted in the opposite flank. At varying time intervals after implantation the rats were killed and the implants removed. Cartilage was assayed for proteoglycan as described below. Where cotton was implanted this was dissociated from the cartilage and immediately weighed (wet weight). The cotton was subsequently reweighed after drying at $37^{\circ} \mathrm{C}$ for $72 \mathrm{~h}$. The granulomatous response induced at the site of implantation was assessed by determining the amount of water (exudate =wet weight of cotton-dry weight of $\bar{s}$ cotton) and granulation tissue (dry weight of $\bar{\square}$ cotton-original weight of cotton) accumulating in the cotton.

DETER M INATION OF CARTILAGE PROTEOG L Y C A N

Cartilage proteoglycan was determined by the $\vec{\circ}$ method of Farndale et al. ${ }^{18}$ Cartilages were di- $\overrightarrow{\vec{H}}$ gested with papain (type III; Sigma Chemical Co) in a digestive buffer for two hours at $55^{\circ} \mathrm{C}$ and the digest reacted with 1,9-dimethylmethylene blue for 을 spectrophotometry. Absorbance values at $535 \mathrm{~nm}$ cr were then compared with a chondroitin sulphate 0 (Sigma Chemical Co) standard curve.

H I S T O L O G Y

Cartilage implants with associated tissues were fixed $\overrightarrow{-}$ in $10 \%$ formol saline and $5 \mu \mathrm{m}$ paraffin sections $\underset{D}{C}$ prepared. Sections were stained with Harris' haema- $\frac{}{\mathbb{D}}$ toxylin and eosin.

\section{Results}

MICRO- AND MACROSCOPIC FEATURES OF SUBCUTANEOUS IMPLANTS

Four days after implantation into subcutaneou tissues of rats the femoral heads with $(2 \mathrm{mg})$ and without cotton could be easily separated from surrounding connective tissue. There were no signs $\frac{\circ}{\mathbb{D}}$ of haemorrhage or necrosis of tissue adjacent to the implants. After four days the implants became

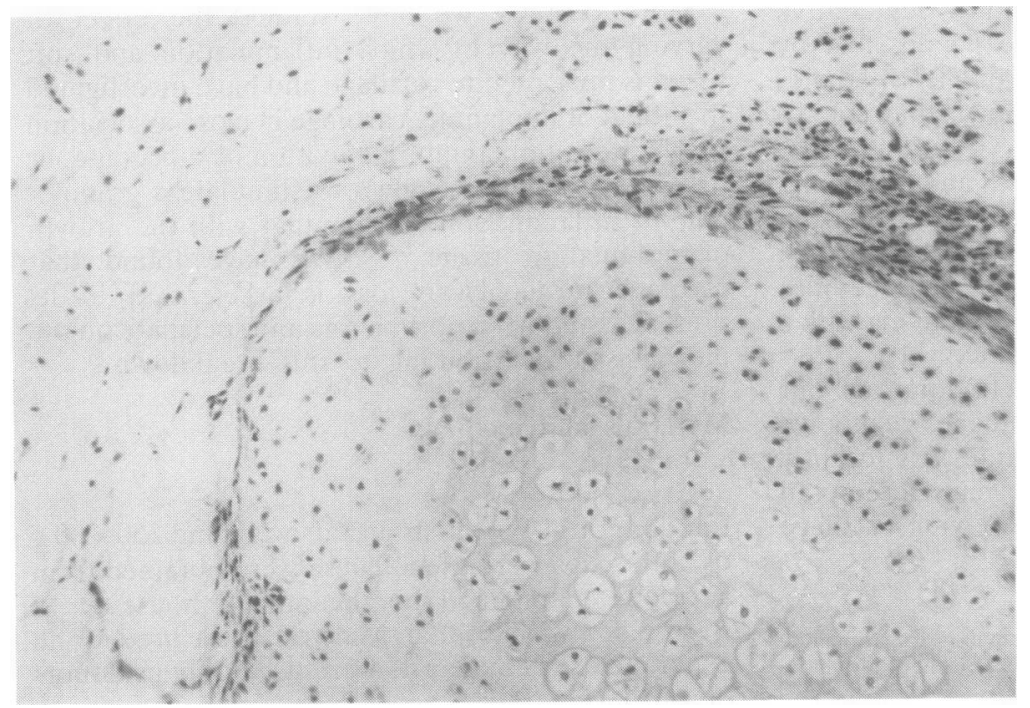

Fig. 1 Femoral head cartilage implant in subcutaneous tissues eight days after implantation. 
progressively bound by connective tissue; those with cotton were more adherent and rigidly held in position by thickening connective tissue on either side. Although the cotton encapsulates could be easily dissociated after the fourth day of implantation, this became increasingly difficult as the duration of implantation increased; implants became firmly encapsulated with granulomatous tissue but there were no macroscopic signs of invasion into cartilage and generally these were recovered intact.

A histological examination of the implants showed that at four days cartilage without cotton was surrounded by connective tissue having the histological appearance of granulation tissue. This was composed of layers of predominantly fibroblastlike cells with interspersed mononuclear cells and capillaries (Fig. 1). The thickness of this tissue varied considerably (approx. 50-100 $\mu \mathrm{m}$ ). Some pigmented cells, presumably haemosiderin laden macrophages, were also seen. Characteristically the tissue was closely packed and adherent to the articular surface of the implanted cartilage but showed less organisation adjacent to the subchrondral areas. The nature of the granulation tissue did not appear to alter significantly when examined at later times.

The connective tissue response to cotton-cartilage implants showed three distinct zones (Fig. 2). Immediately adjacent to the cartilage was a layer of granulation tissue resembling the response seen to cartilage implanted without cotton. Surrounding this was a foreign body granuloma of fibroblasts, mononuclear cells, giant cells, and focal areas of degenerating polymorphonuclear leucocytes. The outer- most zone was again a layer of granulation tissue. At day 4 parts of the granuloma, particularly nearer the cartilage, appeared relatively acellular. By day 8 the granuloma appeared to have matured and did not alter histologically at later times.

Cartilage erosions were more extensive in cottoncartilage implants than in cartilage implanted alone. The pattern of erosions in both cases was, however, similar. Erosions were seen from day 8 onwards and increased in extent with time. In the main the articular surface of implants remained intact with just a few local erosions. The exception to this occurred when there was clear evidence that Tere's ligament had been torn away from its insertion site and given access to invading cells. Most erosions were seen to occur from the subchondral side of the implants, destroying usually the layer of calcified chondrocytes. In cotton implants this process was complete by about day 12; in non-cotton implants it was not always complete at the end of the study. The invading cells had the character of the granulation tissue cells surrounding each cartilage implant. The subchondral side of the articular hyaline cartilage appeared to be spared major erosions. In general the chondrocytes of the epiphyseal disc and the articular hyaline cartilage seemed to be viable throughout the study (Figs 1 and 2).

\section{PROTOGLYCAN LOSS FROM CARTILAGE} IMPLANTS

The proteoglycan content of cartilages in the flanks of rats during the implantation period is shown in Fig. 3. Proteoglycan loss occurred sooner from implants wrapped with cotton $(2 \mathrm{mg})$, beginning

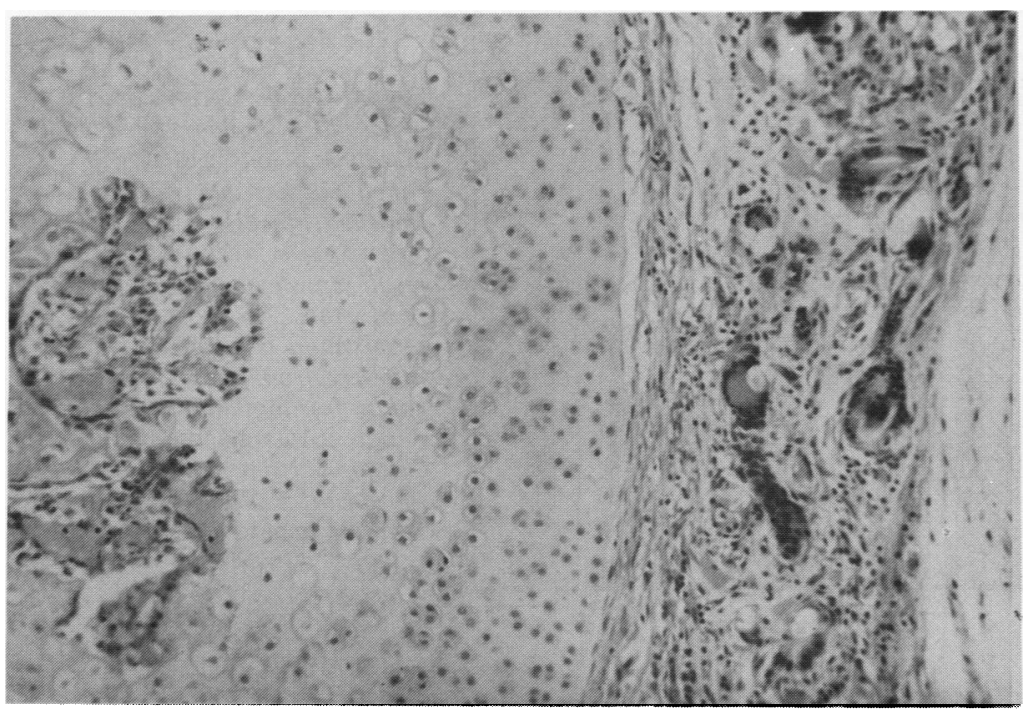

Fig. 2 Femoral head cartilage in cotton granuloma in subcutaneous tissues eight days after implantation. 
768 De Brito, Moore, Adhya, Al-Duaij, Willoughby

four to eight days after implantation and reaching a maximum loss 12 to 16 days later. After 24 days the total loss of proteoglycan from both implants was the same.

In another experiment the effect of increasing the weight of cotton around the cartilage was investigated (Fig. 4). After the first week of implantation there was a significant reduction in the proteoglycan of cartilages bearing cotton, regardless of weight. By

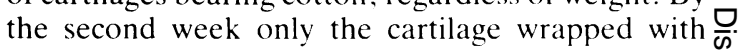
$2 \mathrm{mg}$ of cotton had a significantly lower proteoglycan content than the cotton free control cartilage in the opposite flank. The proteoglycan content of theo cotton free cartilages implanted in animals having 4 and $8 \mathrm{mg}$ of cotton was much lower (but not $\frac{\bar{\rho}}{\bar{D}}$ significantly) than that of the group having $2 \mathrm{mg}$ of $\frac{\mathbb{D}}{\circ}$

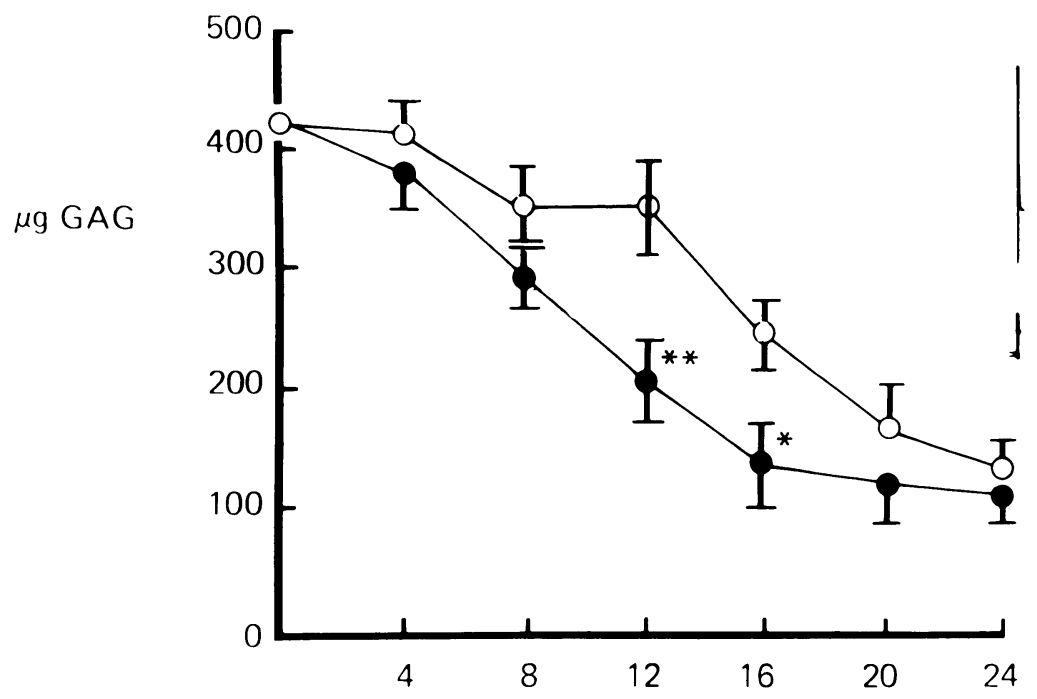

Fig. 3 Time course of proteoglvcan loss from bilateral cartilage implants with and without $\mathrm{O}$ ) cotton $(2 \mathrm{mg})$. Each result represents the mean $\pm S E M$ of six rats. $p<0.05$ $* * p<0 \cdot 01$; this result is significantly different from the corresponding colton free result using Student's t test. $G A G=$ glvcosaminog/vcan.

Days after implantation in subcutaneous tissues

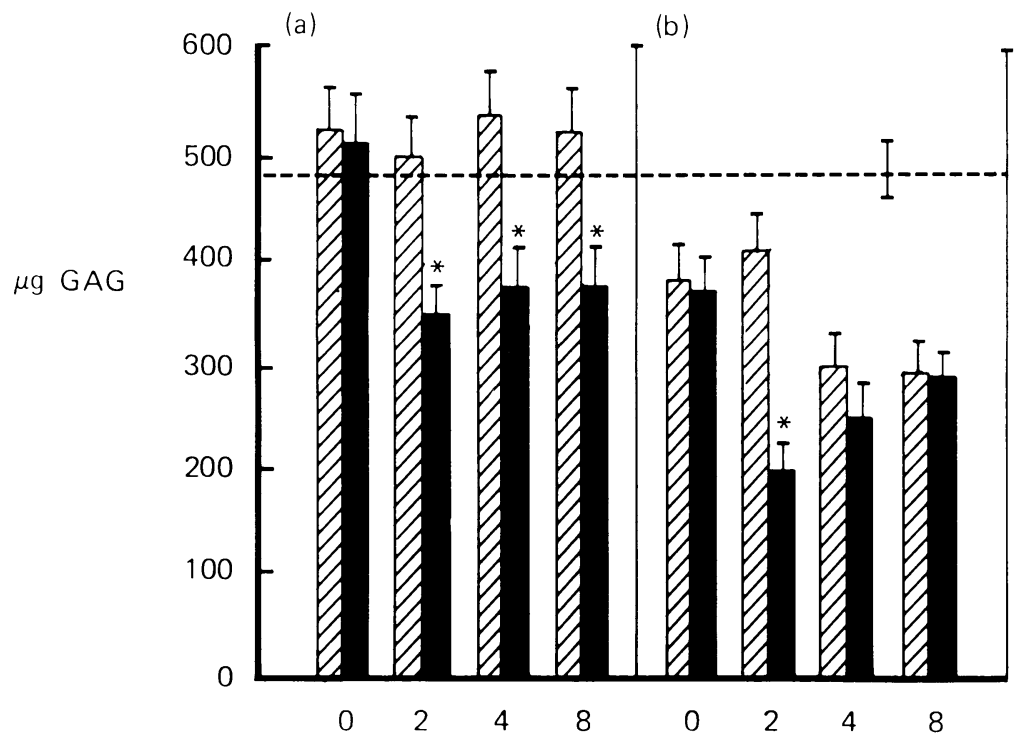

Fig. 4 Proteoglycan content of cartilage implanted bilaterally in subcutaneous tissues with (filled blocks) and without (hatched blocks) cotton (a) one and (b) two weeks later. Each result represents the mean $\pm S E M$ of six rats. ${ }^{*} p<0.05$; this observation is significantly different from the corresponding cotton free implant using Student's o t test. $G A G=$ glycosaminoglvcan. The dotted line represents the mean $\pm S E M G A G$ of the non-implanted stored control.

mg cotton added to implant 
$\mathrm{mg}$

Exudate

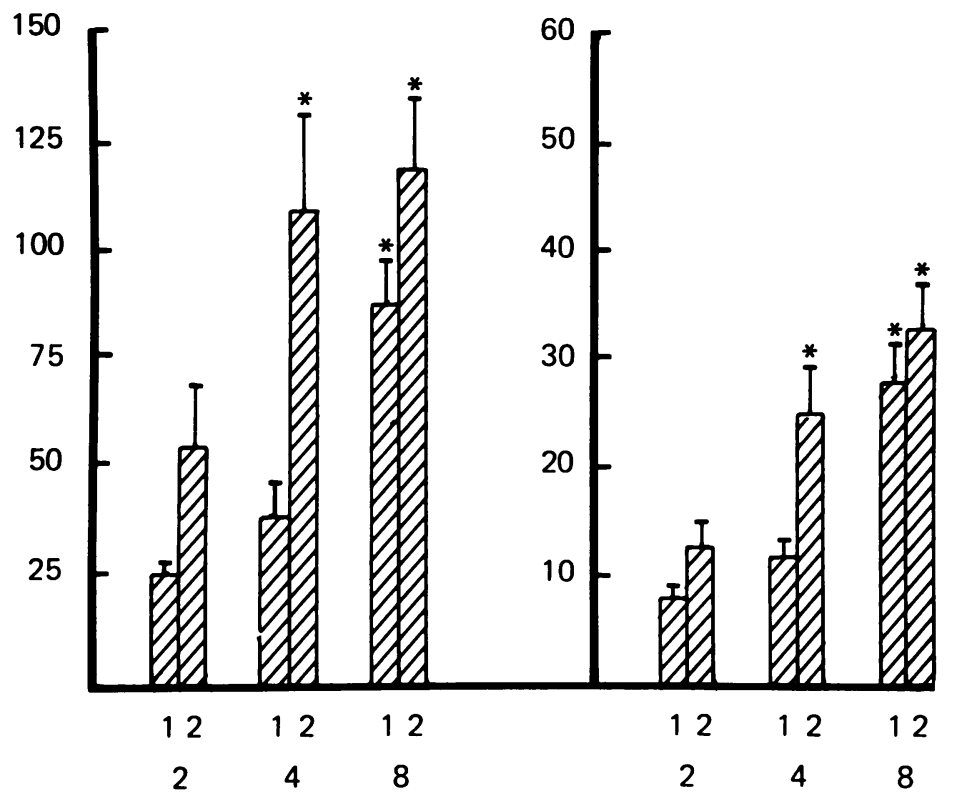

Fig. 5 Quantitative assessment of the granulomatous response induced by different weights ( $\mathrm{mg}$ ) of cotton after implantation with cartilage in subcutaneous tissues. Cotton-cartilage implants were removed at one and two weeks after implantation. Exudate (water content $)=$ wet weight of cotton-dry weight of cotton; granulation tissue = dry weight of cotton-original weight of cotton. Each result represents the mean $\pm S E M$ of six implants. ${ }^{*} p<0.05$; this result is significantly different from the corresponding $2 \mathrm{mg}$ result.

Week after implantation (above); weight of cotton (below)

cotton and the group with no cotton. There was, however, an increase in the accumulation of inflammatory fluid and the formation of granulation tissue in the implants after one and two weeks which was related to the weight of the cotton (Fig. 5).

\section{Discussion}

The present study confirms in vitro observations on the contribution made by mononuclear cells and fibroblasts in the destruction of cartilage. ${ }^{4-9}$ Homologous femoral head cartilage implanted subcutaneously in rats developed fewer surface erosions and lost less proteoglycan than similar cartilage implants encapsulated with cotton. Both implants, however, became enveloped by a granulation tissue composed predominantly of layers of fibroblasts, but the principal difference between the two was the distinctive granulomatous cellular response beneath induced by cotton. Mononuclear and multinucleated giant cells were part of this response. In this respect the connective tissue response elicited by cotton could be similar to that induced by pannus in the early phase of rheumatoid arthritis, as described by Shiozawa et al. ${ }^{19}$ These workers observed that cartilage became overlaid with fibroblast-like cells before macrophage-like cells which were present beneath began to invade the cartilage. The accelerated breakdown of cartilage produced by cotton would appear to be caused by the granulation tissue cells activated by humoral and cellular products of the developing granuloma. Immunological mechanisms of rejection may contribute to this breakdown. The role of interleukin 1 in this model of cartilage breakdown is presently being pursued, but the absence of enlarged chondrocyte lacunae after substantial proteoglycan loss would appear to exclude any effect via the chondrocyte. ${ }^{8}$

The articular surface of cartilage implants remained relatively intact throughout the implantation period (24 days). Erosions were commonly found in the subchrondral plate, their size and number increasing with time. This contrasts somewhat with the situation in the rheumatoid joint, where although proliferation of granulation tissue at the margins of the joint is an important cause of subchondral erosions, the articular surface is also breached. ${ }^{12}$ It is possible that the period of implantation of cartilages in this study may not have been sufficiently long for this to happen. In a 
histological study of the development of arthritis in a spontaneously developing animal model, the MRL/1 mouse, O'Sullivan et al found that the earliest pathological change appearing in joints was synovial cell proliferation in the joint recesses, with associated subchondral bone destruction producing marginal erosions. ${ }^{20}$ The articular cartilage was spared during this time, though a few weeks later it was affected. It was interesting that these changes occurred without the presence of subsynovial or periarticular inflammation.

The association of inflammation with destruction of cartilage in rheumatoid arthritis remains a controversial issue. In experimental rodents the implantation of femoral head cartilage in immunologically $^{14}$ and non-immunologically ${ }^{13} 15$ inflamed subcutaneous air pouches was not found to accelerate proteoglycan loss. Swingle and Shideman described three phases of the inflammatory response to implanted cotton pellets: a transudative phase (zero to three hours), an exudative phase (three to 72 hours), and a proliferative phase (four days onwards). ${ }^{17}$ The first two components were essentially increases in fluid accumulation of the pellet coupled with a large polymorph presence and only a few mononucleated cells. In the proliferative phase polymorph numbers declined and lymphocyte, macrophage, and fibroblast numbers increased. This also coincided with the appearance and increased synthesis of collagen and lysosomal enzymes. ${ }^{21} 22$ The time course of accelerated loss of proteoglycan by cotton correlates with the latter phase and it is possible that this may be due to the increased presence of degradative enzymes. Increasing the weight of cotton, however, did not cause further breakdown of cartilage, suggesting that the intensity of the granulomatous inflammatory process may not be important for cartilage proteoglycan loss. This could be explained by an increased production of proteolytic enzyme inhibitors, ${ }^{23}$ which could also account for the fact that cartilages in inflamed air pouches fail to degrade faster. Wrapping cartilages with less than $2 \mathrm{mg}$ of cotton was not possible, consequently limiting a complete cotton dose related study.

We would like to thank $\mathrm{Mr} \mathrm{K}$ A Law for valuable technical assistance and the Arthritis and Rheumatism Council for financial support.

\section{References}

1 Gardner D L. The pathology of rheumatoid arthritis. London: Arnold, 1972.

2 Sokoloff $\mathrm{L}$. The pathology of rheumatoid arthritis and allied disorders. In: Hollander J L, McCarthy D J, eds. Arthritis and allied disorders. Philadelphia: Lea and Febiger, 1972: 309-22.

3 Zvaifler N J. The immunopathology of joint inflammation in rheumatoid arthritis. Adv Immunol 1973; 16: 265-336.
4 Vaes G, Hauser P, Huybrechts-Godin G, Peeters-Joris. Cartil- $\bar{\Xi}$ age degradation by macrophages, fibroblasts and synovial cells $\square$. in culture. An in-vitro model suitable for studies on rheumatoid $\bar{s}$ arthritis. In: Willoughby D A, Giroud J P, Velo G P, eds. Perspectives in inflammation. Future trends and developments. Lancaster: MTP Press, 1977: 115-29.

5 Vaes G, Huybrechts-Godin G, Hauser P. Lymphocytemacrophage-fibroblast cooperation in the inflammatory de- $\overline{\bar{\sigma}}$ gradation of cartilage and connective tissue. Agents Actions $\frac{\bar{s}}{\bar{\sigma}}$ 1980; 7: 100-8.

6 Dayer J M, Goldring S R, Robinson D R. Cell-cell interactions and collagenase production. In: Woolley D E, Evanson J M, eds. Collagenase in normal and pathological connective tissues. $\overrightarrow{0}$ Chichester: Wiley, 1980: 83-104.

7 Krane S M, Amento E P. Cellular interactions and control of $\overrightarrow{-}$ collagenase secretion in the synovium. $J$ Rheumatol 1983; $10 \mathrm{\sigma}$ (suppl 11): 7-12.

8 Dingle J T. The role of catabolin in the control of cartilage $\frac{2}{2}$ matrix integrity. $J$ Rheumatol 1983; 10 (suppl 11): 38-42. A

9 Saklatvala J, Pilsworth L M C, Sarsfield S J, Gavrilovic J, Heath J K. Pig catabolin is a form of interleukin 1. Biochem 1984; 224: 461-6.

10 Rainsford K D. Effects of antiinflammatory drugs on catabolinc induced cartilage destruction in vitro. Int J Tissue React 1985:을 VII: $123-6$.

11 Edwards J C W, Sedgwick A D, Willoughby D A. The $\vec{c}$ formation of a structure with the features of synovial lining byd subcutaneous injection of air. An in vivo tissue culture system? J Pathol 1981; 134: 147-56.

12 Sedgwick A D, Sin Y M, Edwards J C W, Willoughby D A Increased inflammatory reactivity in newly formed lining tissue $\underline{\mathbb{D}}$ $J$ Pathol 1983; 141: 483-95.

13 Sin Y M, Sedgwick A D, Willoughby D A. Studies on क्षिc mechanisms of cartilage degradation.J Pathol 1984; 142: 23 \$్య

14 Willoughby D A, Al-Duaij A Y, De Brito F B, Sedgwick A Effect of therapeutic agents on immune inflammation and cartilage degradation [Abstract]. Int $J$ Immunopharmaco 1985; 7: 627.

15 Sedgwick A D, Moore A R, Al-Duaij A Y, Edwards J C WO Willoughby D A. Studies into the influence of carrageenar? induced inflammation on articular cartilage degradation using implantation into air pouches. Br J Exp Pathol 1985; 66: 445-53 $\overrightarrow{\vec{T}}$

16 Meier R, Schuler W, Desaulles P. Zur Frage des mechanismus der hemmung des Bindegewehswachtsums durch Cortisone Experientia 1950; 6: 469-71.

17 Swingle K F, Shideman F E. Phases of the inflammator response to subcutaneous implantation of a cotton pellet and modification by certain anti-inflammatory agents. $J$ Pharmaco Exp Ther 1972; 183: 226-34.

18 Farndale R W, Sayer C A, Barrett A J. A direct spectrophoto metric microassay for sulphated glycosaminoglycans in cartilage culture. Connect Tissue Res 1982; 9: 247-51.

19 Shiozawa S, Shiozawa K, Fujita T. Morphologic observation in the early phase of the cartilage-pannus junction. Light and electron microscopic studies of active cellular pannus. Arthritis Rheum 1983; 26: 472-8.

20 O'Sullivan F X, Fassbender H G, Gay S, Koopman W J을 Etiopathogenesis of the rheumatoid arthritis-like disease in MRL 1 mice. 1. The histomorphologic basis of joint destruces tion. Arthritis Rheum 1985; 28: 529-36.

21 Freeman P C, Mangan F R, Watkins O K. Some effects o⿻ hydrocortisone on the early development of the rat cotton pellew granuloma. Biochem Pharmacol 1979; 28: 573-8.

22 Eichorn J H, Sniffen R C. Influence of cortisol and insulin ôn in vitro incorporation of amino acids into protein of granulome tissue. Endocrinology 1964; 75: 341-51.

23 Murphy G, Reynolds J J. Current views of collagen degradation. Progress towards understanding the resorption of connec⿱D tive tissues. Bio Essays 1985; 2: 55-60. 